\title{
A construção do maniqueísmo político no discurso jornalístico brasileiro contemporâneo: uma proposta de letramento crítico ancorada em uma análise sistêmico-funcional
}

\author{
Diego Abreu \\ Pontifícia Universidade Católica do Rio de Janeiro - PUC-Rio/CNPq
}

\begin{abstract}
Resumo
O objetivo deste trabalho é articular os preceitos teórico-analíticos da Linguística Sistêmico-Funcional (HALLIDAY, 1994), em seu diálogo constante com o Sistema de Avaliatividade (MARTIN; WHITE, 2005), com a construção do letramento crítico em língua materna. Para tanto, apresento uma análise acerca do processo de (re-)construção de identidades em dois textos jornalístico-políticos contemporâneos. Nesse sentido, baseio-me na noção de nós e os outros (DUSZAK, 2002) com o objetivo de compreender como identidades de pertencimento a grupos vêm sendo construídas no discurso do jornalismo político brasileiro atual. A análise desenvolvida sugere que a opção por alguns pronomes ou a escolha lexical de certos atributos associados a determinados indivíduos ou instituições ressaltam o seu pertencimento (ou não-pertencimento) a grupos sociais que podem ter suas ações e posturas consagradas ou atacadas de acordo com essas identidades construídas no texto.
\end{abstract}

Palavras-chave: linguística aplicada, linguística sistêmico-funcional, letramento crítico.

\begin{abstract}
The goal of this paper is to articulate the theoretical and analytical assumptions of Systemic Functional Linguistics (HALLIDAY, 1994) in constant dialogue with the Appraisal Theory (MARTIN; WHITE, 2005), with the construction of critical literacy in the first language. For this purpose, an analysis is presented of the process of (re-)construction of identities in two texts of contemporary political journalism. In this regard, aiming at clarifying how ingroupness identities are constructed in current Brazilian political journalism discourse, this work is based on the notion of us and the others (DUSZAK, 2002). The analysis suggests that the option for some pronouns or the lexical choice of certain attributes related to particular individuals or institutions highlights the notion of ingroupness (outgroupness) for certain social groups whose actions and stances may be sanctioned or attacked according to these constructed identities.
\end{abstract}

Keywords: applied linguistics, systemic functional linguistics and critical literacy.

\section{INTRODUÇÃO}

Ofensas, xingamentos e acusações; esses são alguns dos percalços que se colocam no caminho daqueles que se arriscam a posicionar-se em meio à efervescência caótica do cenário 
político brasileiro atual. Cabe aqui uma breve contextualização histórica: o período em que me debruço sobre essas questões é o segundo trimestre de 2016. Momento de relativa culminância de todas as antíteses, oposições e dicotomias políticas que vêm aquecendo o Brasil nos últimos tempos.

Todos esses conflitos encontram materialidade e eco no discurso da imprensa, merecendo destaque, nesta pesquisa, a mídia impressa. Considerando a impossibilidade da neutralidade do discurso jornalístico, o texto midiático é veiculado de maneira enviesada com base em suas crenças e ideologias ou nos interesses específicos dos diversos profíssionais do jornalismo ou veículos de comunicação. Entretanto, os posicionamentos políticos dos autores de textos jornalísticos (supostamente imparciais) deixam marcas e rastros reveladores que podem ser acessados através de ferramentas analíticas disponibilizadas por diversas vertentes dos estudos linguísticos. No presente trabalho, especificamente, me ancoro em alguns desses instrumentos e aportes teóricos fornecidos pela literatura da área. Busco na Linguística Sistêmico-Funcional (doravante LSF) (HALLIDAY, 1994), em seu fértil diálogo com o Sistema de Avaliatividade (MARTIN; WHITE, 2005), insumos analíticos, com a ajuda dos quais disponho de maior suporte ferramental para me debruçar sobre os textos aqui observados. No que tange o processo de construção identitária, nosso apoio será a noção de nós e outros (DUSZAK, 2002).

Partindo da assunção do viés inerentemente político da educação, torna-se imprescindível fomentar o diálogo entre esse arcabouço teórico-analítico, que nos permite compreender de forma mais ampla e aprofundada diferentes textos (e suas respectivas relações com os contextos que os envolvem), e o letramento crítico discente, construindo, assim, uma ponte importante entre a academia e a sala de aula. O afã de promover essa conversa é a motivação catalisadora da presente pesquisa. Busco, através desse esforço teórico, ofertar um exemplo de análise, pautada no arcabouço teórico apresentado acima, que visa ser integrada a uma prática de letramento crítico. Esse diálogo oferecerá ao aluno um ferramental de análise textual e contextual, em seus aspectos sociais e políticos, que lhe permitirá encontrar em diferentes textos as "pegadas" ideológicas deixadas por seus respectivos autores, dando a esses alunos a possibilidade de posicionar-se de forma mais consistente diante dessas leituras. 


\section{ARGUMENTAÇÃO E LETRAMENTO CRÍTICO}

Por se tratar de um conceito amplo e aplicado em diversos campos do conhecimento, várias definições são atribuídas à argumentação. Apesar dessa pluralidade, um aspecto intrínseco ao argumentar é o seu viés social. Dessa forma, parece conveniente apoiar-nos em Abreu (2013) quando a autora afirma que "a argumentação é uma prática de cunho social e é essencialmente dialógica, pois ocorre nas relações sociais em que a troca é mediada a partir do uso da linguagem." Portanto, a argumentação não se restringe apenas ao orador com a palavra; o auditório não adota uma atitude passiva de receptor dos argumentos, mas ajuda a construí-los, corroborando ou refutando-os. Da mesma maneira, a plateia precisa estar disposta a ouvir ou deixar-se influenciar pelos argumentos apresentados pelo orador, ou como coloca Breton (2003, p. 53) "adotar uma postura de debate ou se deixar ser convencida." Em busca do estabelecimento dessa relação favorável com o auditório, os argumentos são empregados pelo orador em dois momentos distintos, sendo o primeiro a etapa de enquadramento do real e a segunda, vínculos. Esse processo é denominado por Breton de duplo gatilho argumentativo. Dessa forma, o orador busca, na primeira etapa, estabelecer uma realidade compartilhada com seus ouvintes ou leitores enquanto, na segunda etapa, prepara o terreno para relacionar o consenso estabelecido e a opinião ou proposta a ser apresentada para a plateia (ABREU, 2013).

A visão de letramento crítico sobre a qual essa pesquisa se apoia constitui-se da articulação, realizadas por Cervetti, Pardales e Damico (2001), de três perspectivas distintas que dialogam devido a suas naturezas inerentemente sociais. Um desses olhares, o da crítica social, se opõe a uma perspectiva essencialista de letramento, pautada na ideia da existência de verdades apriorísticas no mundo, que ambiciona habilitar o aluno a constatar os significados já existentes e não (des-/re-)construí-los. Os teóricos da crítica social buscam deslegitimar essa visão tecnicista ao dar importância central à função de construção da realidade desempenhada pelo discurso em seu contexto social. Integrada a essa perspectiva, encontra-se a visão pós-estruturalista, que articula o aspecto sócio-construtivo do discurso e do letramento com as estruturas capilarizadas de poder que estruturam a sociedade.

Por fim, a essas perspectivas, relaciona-se a pedagogia freiriana na qual "parte-se do pressuposto que todas as práticas de letramento devem ter como dedicação fundamental a busca por justiça social, liberdade e equidade" (CERVETTI; PARDALES; DAMICO, 2001). Dessa forma, o entendimento de letramento crítico ao qual esse trabalho se alinha privilegia os aspectos sociais do discurso, cujas marcas encontram-se presentes em todos os textos, com 
vias à promoção de um processo de transformação política que busque a construção de uma sociedade menos desigual e a contestação das estruturas de dominação.

\section{LINGUÍSTICA SISTÊMICO-FUNCIONAL E O SISTEMA DE AVALIATIVIDADE}

A LSF, desenvolvida por Halliday a partir da década de 1960, é uma teoria que parte da perspectiva sociossemiótica da linguagem. Halliday afirma que a gramática funcional caracteriza-se por ser uma gramática natural (HALLIDAY, 1994) ao preconizar visões e explicações da língua, tendo como horizonte o uso real feito pelos indivíduos em sociedade. $\mathrm{O}$ caráter sistêmico dessa teoria é evidenciado pelo entendimento da língua como um sistema semiótico de opções, vinculadas entre si (por isso formando um sistema), que implica, nos falantes ou escritores de uma língua, a realização de escolhas paradigmáticas de viés léxicogramatical no que tange ao teor da mensagem a ser representada e ao tipo de relação estabelecida entre os participantes da interação.

Um ponto central na teoria proposta por Halliday é a forma como o autor entende a linguagem a partir de uma estrutura estratificada. O primeiro grau de estratificação pode ser observado na distinção entre dois níveis: o extralinguístico e o linguístico. No primeiro, encontram-se o contexto de cultura e o contexto de situação. Segundo Nóbrega e Abreu (2015, p. 3) "O contexto de cultura é amplo e envolve todos os possíveis sentidos de uma dada cultura e o de situação, por outro lado, é particular, pois abrange a realização da linguagem em determinado contexto.” O contexto de situação estrutura-se sobre três variáveis - o campo, relações e modo - que estão diretamente relacionadas às três metafunções da instanciação semântica (um dos três planos que estratificam o nível linguístico): ideacional, interpessoal e textual, respectivamente. Essas três metafunções são descritas abaixo nas palavras de Sobrinho (2015, p. 59):

\footnotetext{
A função ideacional refere-se à representação e organização das experiências do mundo interior e exterior do indivíduo; a função interpessoal diz respeito às relações entre os participantes e seus papéis sociais; e a textual está relacionada à construção da mensagem, à distribuição da informação, conjugando, pois, a duas funções anteriores.
}

Essas metafunções ensejam instanciações nas escolhas de palavras e estruturas, constituindo assim três sistemas de realização no nível léxico-gramatical: o sistema de transitividade (componente ideacional), o sistema de modo (componente interpessoal e o sistema de tematização (componente textual) (GOUVEIA, 2009, p. 30). A metafunção interpessoal ainda conta com o Sistema de Avaliatividade que se situa "no campo da 
avaliação das atividades interpessoais, no nível da semântica do discurso" (NÓBREGA, 2009, p. 90). Para ele que volto minha atenção adiante.

\section{Sistema de Avaliatividade}

Desenvolvido por um grupo de pesquisadores australianos sob a coordenação de Martin, o Sistema de Avaliatividade configura-se como uma ferramenta de análise textual, podendo ser definido como

um conjunto de significados interpessoais que se debruça sobre os mecanismos de avaliação veiculados pela linguagem, configurados em um sistema que oferece aos usuários possibilidades de utilizar itens avaliativos em suas interações cotidianas (VIAN JR, 2011, p. 11)

Ao tratar da avaliação, é necessário salientar a sua ligação com o aspecto interpessoal da interação através da linguagem. Toda construção afetiva de emoções e sentimentos no discurso encontra sua razão de ser na busca da solidariedade da parte do ouvinte/leitor. Dessa forma, o Sistema de Avaliatividade instrumentaliza uma investigação que vai além dos significados presentes na oração, indagando a respeito dos motivos e interesses pessoais, que têm sua raiz de natureza social, que exercem influência no posicionamento, aproximação ou afastamento de determinados indivíduos ou coisas do mundo.

A Avaliatividade encontra-se no nível da semântica do discurso, associada ao elemento Relações no plano do Registro, ao lado de outros dois sistemas: Negociação e Envolvimento (SOBRINHO, 2015, p. 77). O Sistema de Avaliatividade, além de já estar inserido em outras estratificações é, por sua vez, estratificado em outros subsistemas: Atitude, Engajamento e Gradação.

A Gradação trabalha a serviço dos outros dois subsistemas, lidando com o aspecto da intensidade (força) com que os elementos avaliativos são construídos no texto ou o quão focalizados eles são (foco). O Engajamento está relacionado com a multiplicidade de vozes presentes no texto e o grau de abertura de que essas vozes dispõem. As investigações desse subsistema articulam-se com o conceito de heteroglossia/monoglossia (Bakhtin, 2003). Finalmente, a Atitude trata das emoções, sentimentos e posicionamentos expostos no texto com relação ao próprio autor/falante, seu(s) interlocutor(es)/leitor(es) e as demais coisas do mundo, dividindo-se em três subsistemas: Afeto, Julgamento e Apreciação.

O Afeto está intimamente vinculado às emoções e sentimentos do autor expostos em relação à pessoa, coisa, ambiente, ideia e posicionamentos no texto analisado. O Julgamento configura-se por sua natureza ética, permitindo ao autor desferir avaliações de cunho moral 
acerca do comportamento de seu(s) interlocutor(es) ou terceiros. Essa atitude do autor pode ensejar julgamentos de duas espécies: estima social e sanção social. A Apreciação preconiza um juízo de natureza estética acerca de algum elemento não entendido, no contexto em questão, como um sujeito. Nesse sentido, para poder encontrar um apoio mais sólido no ferramental de análise apresentado nesse capítulo, é preciso fomentar o diálogo desses construtos analíticos com uma perspectiva teórica que discorra acerca da construção de identidades através do discurso. Tratarei dessa questão na próxima seção desse trabalho.

\section{Nós E OUTROS: A CONSTRUÇÃO DAS IDENTIDADES POLÍTICO- IDEOLÓGICAS ATRAVÉS DO ALINHAMENTO E DA OPOSIÇÃO}

As crenças, expectativas e posicionamentos compartilhados aproximam pessoas, fomentando o sentimento de inclusão em grupos sociais. Nos sentimos confortáveis e protegidos quando reunidos com outros indivíduos que carregam bandeiras semelhantes às nossas. Da mesma forma, um sentimento de desconforto nos assola ao percebermos a existência de pessoas que não se alinham aos nossos valores, que formam grupos dos quais nos encontramos excluídos.

Todas essas observações encontram abrigo teórico no conceito de nós e outros (DUSZAK, 2002). As identidades, construídas na interação social, têm como insumos principais certos sinais de (não) pertencimento a determinados grupos. Dentre esses sinais, que transpassam simbolicamente nossos costumes, aparência e ações, a linguagem se destaca como o mais importante. Nossos discursos nos distanciam ou aproximam de nossos interlocutores, tendo em vista as ideias nele chanceladas e as marcas e símbolos por ele carregados. A esse respeito, Duszak (2002, p. 2) afirma que o pertencimento a múltiplos grupos sociais deve-se "ao grande número de papéis que as pessoas assumem, normalmente, no curso de suas vidas sociais e à variedade de necessidades que eles querem satisfazer através da ação em comum." Além de várias, as identidades também são líquidas (BAUMAN, 2008). Esse aspecto fluido das construções identitárias impede sua categorização rígida.

A maneira principal como toda essa complexidade de identidades construídas socialmente na interação aflora e se deixa apresentar é através da linguagem. Através de construtos linguísticos, dispomos de recursos para indicar quão próximas ou distantes se estabelecem as relações sociais a partir da ideia de que nós somos diferentes deles, os outros. Essa distinção pode ser usada como ferramenta, na materialidade do discurso, para (des-) legitimar valores de inclusão ou exclusão em certos grupos sociais. Assim, "Uma das formas 
de construção de ingroupness é o uso do pronome nós, estando sempre em oposição ao eles (outgroupness).” (NÓBREGA; MAGALHÃES 2012, p. 72).

Apresentado o terreno teórico sobre o qual essa pesquisa se edifica, posso me debruçar com mais consistência analítica sobre os textos que compõem os dados desse artigo. A seção seguinte será devotada a esse labor.

\section{ANÁLISE DE DADOS}

Visando dar conta da investigação proposta de forma sistematizada, organizo a análise em dois eixos temáticos: Análise da Atitude na construção de identidades a partir da distinção nós e outros e Análise do Engajamento na construção de identidades a partir da distinção nós e outros. No primeiro eixo, me debruçarei sobre a forma como as categorias de Afeto, Julgamento e Apreciação influem no processo de construção identitária nos dois textos. No segundo eixo, o foco da análise recai sobre a categoria do Engajamento. A análise da categoria de Gradação será articulada aos dois eixos sem a necessidade da construção de um eixo específico, considerando que esse subsistema do Sistema de Avaliatividade caminha lado a lado com os outros dois (Atitude e Engajamento), complementando-os em sua intensidade e amplitude focal.

O corpus dessa pesquisa é composto por dois textos, que foram escolhidos por mostrarem-se representativos do discurso fomentador da polarização política - objeto de interesse desse trabalho. Uma série de textos jornalísticos de cunho político disponibilizados em versões online de revistas de grande circulação nacional foi analisada. Alguns critérios de refinamento na seleção dos textos que comporiam o corpus final foram adotados. Primeiramente, foi realizada a seleção de um grupo de textos que, de alguma forma, versassem sobre o momento político atual; seja na forma de uma análise conjectural ou através de um comentário acerca de um fato ocorrido à luz desse cenário. Em seguida, foram destacados os textos onde o autor se posicionasse de forma mais marcada, evidenciando alguma dicotomia ou oposição política como direita/esquerda ou governo/oposição. O terceiro momento de refinamento do corpus configurou-se na escolha dos textos onde, partindo da perspectiva da distinção entre nós e outros (DUSZAK, 2002), foi possível observar, além da afiliação do autor a um determinado grupo, o ataque deliberado do mesmo aos "adversários", fomentando a construção de identidades através da aproximação a um certo grupo e o distanciamento violento do grupo antagonizado. 
O texto $1^{1}$, cujo título é $O$ lado virtuoso da crise: a esquerda vira reduto de incompetentes, aproveitadores e vagabundos trata da cerimônia e ato de repúdio ao afastamento da Presidenta Dilma Rousseff, evidenciando aspectos negativos desse evento. Dentre eles, o autor ressalta o fato de uma equipe jornalística ter sido agredida por manifestantes favoráveis ao governo da presidenta afastada. $\mathrm{O}$ texto $2^{2}$, intitulado $O$ impeachment e a onda de autoritarismo, apresenta, não um fato específico, mas uma série de fatos. Na visão editorial defendida pela autora, tais acontecimentos se configurariam em exemplos factuais de atos antidemocráticos e violentos protagonizados por setores conservadores e patriarcais da sociedade brasileira.

\section{Análise da Atitude na construção de identidades a partir da distinção nós e outros}

A polarização política fomentadora de identidades alicerçadas em ideologias antagônicas, observada já no título das duas matérias, é corroborada em diversos outros trechos ao longo de ambos os textos. Abaixo, inicio a análise apresentando alguns fragmentos que exemplificam esse posicionamento discursivo:

\section{Trecho 1}

\begin{tabular}{l}
\begin{tabular}{|l|l|}
\hline 5 & A própria imprensa acabou dando pouco destaque ao acontecido porque, \\
6 & infelizmente, parte considerável do jornalismo é vítima de uma espécie de \\
7 & síndrome de Estocolmo quando o assunto é o PT: sente atração pelo seu \\
8 & sequestrador. Mas, aqui, a questão terá a devida visibilidade.
\end{tabular} \\
\hline
\end{tabular}

Trecho 2

\begin{tabular}{l|l|}
\hline 7 & Assistimos a atos inconstitucionais por aqueles que deveriam aplicar a lei, \\
8 & uma cobertura midiática enviesada, um Congresso que transformou a \\
9 & votação de um processo já ilegítimo num show de horror e falta de respeito à \\
população.
\end{tabular}
Texto 2: Carta Capital online, $11 / 05 / 2016$

A distinção baseada na noção de nós e outros defendida pelo autor do texto 1 é construída, no trecho 1, em um espaço social específico: a imprensa ou, mais especificamente, uma parte dela composta por jornalistas especializados em política. Nesse sentido, uma linha

\footnotetext{
${ }^{1}$ Retirado da Revista Veja online, edição do dia 13/05/2016.

2 Retirado da Revista Carta Capital online, edição do dia 11/05/2016.
} 
é traçada, tratando de distinguir o grupo ao qual o autor se afilia e os outros, cuja conduta é sistematicamente depreciada. Aqui, o escritor lança mão de um julgamento negativo de alta gradação, atribuindo características doentias a uma determinada parte da imprensa que, na visão do autor, seria molestada pelo PT, mas acabaria, de certa forma, tomada por uma certa obsessão afetiva ao tratar desse partido.

No entanto, enquanto o juízo de valor erigido pelo autor sofre uma gradação de força ao abrigar uma comparação do posicionamento de alguns jornalistas a um comportamento psicótico, tal julgamento também é atenuado a partir da escolha pelo item lexical vítima que, ao retirar a uma parte da agência dos indivíduos apreciados (afinal, eles não optaram por sofrer da Síndrome de Estocolmo, não passam de vítimas), diminui o peso repreensivo do discurso. Essa atenuação observada no trecho 1 pode ter suas raízes em um impulso corporativista e de autopreservação do autor que, mesmo discordando veementemente das ideias e das atitudes de seus colegas, alivia a rispidez da sua crítica pelo alvo se tratar de pessoas que compartilham traços identitários com ele (exercem a mesma profissão).

No mesmo momento em que o autor critica a prática de seus pares, fagulhas de julgamento negativo também são dirigidas ao Partido dos Trabalhadores, cuja imagem nesse momento construída é, mais uma vez, associada ao mundo da contravenção e do crime, configurando-se em um juízo de sanção social. Dessa vez, a natureza da relação do PT com a imprensa é comparada a de um sequestrador que priva sua vítima da liberdade e em retribuição - o que torna a situação mais inaceitável para o autor - ainda goza de um tratamento benigno de sua vítima (aqui representado pelo termo atração, uma metáfora gramatical que remete à sedução).

Evidenciando a distinção construída pelo autor no trecho 1 entre duas vertentes da imprensa (aqui analisada através da lente teórica de nós e outros [DUSZAK, 2002]), um julgamento positivo é veiculado a respeito de uma parte da imprensa, na qual o autor se inclui, que não vira as costas para as ações deploráveis do PT ou, em outras palavras, que não sofre de Síndrome de Estocolmo pelo partido do governo. Afirmando que aqui, a questão terá a devida visibilidade, o autor coloca o veículo midiático onde ele se encontra (e, consequentemente, a si próprio) na posição de defensor da liberdade da imprensa e cumpridor do dever jornalístico de informar os seus leitores (incluídos no grupo nós) acerca dos atos recrimináveis do PT (eles). Para sustentar seu argumento, o autor recorre a uma apreciação acerca do valor jornalístico do acontecimento mencionado.

No trecho 2, o discurso também é habilmente manipulado pela autora visando legitimar determinadas construções de identidades e afiliações enquanto elementos sociais de 
posicionamentos antagônicos aos defendidos pela autora são criticados. Assim como no excerto 1 , a autora também tece um julgamento negativo de estima social acerca da cobertura de parte da mídia acerca, dessa vez, não de um evento específico, mas de uma onda de acontecimentos negativamente descritos. Ao depreciar a cobertura de alguns jornalistas, atribuindo a esta cobertura a qualidade de enviesada, a autora, também sendo jornalista, distancia-se do grupo de profissionais que dão um olhar tendencioso aos fatos relatados, afiliando-se ao grupo cuja perspectiva jornalística não é enviesada, ou seja, atem-se com mais fidelidade a uma suposta posição de neutralidade.

No entanto, cabe ressaltar que o julgamento negativo atribuído ao comportamento profissional de parte da mídia encontra-se contido dentro de uma crítica mais abrangente, dirigida a determinados setores da sociedade que têm, no cenário político contemporâneo, exercido notável influência - de caráter pernicioso, segundo a visão observada no discurso da autora. Assim, temos uma clara distinção, que pode ser concebida através da noção de nós $x$ outros. De um lado, a autora elabora a imagem de uma reunião de agentes políticos e sociais que, organizados em uma espécie de conluio antidemocrático, agem contra os interesses majoritários da população. Do outro lado dessa arena, delimitada de forma tautológica, a autora constrói uma identidade de grupo (explicitada na conjugação em primeira pessoa do plural do verbo assistimos) que se distancia desse espetáculo protagonizado por eles ao colocar-se na posição de observadores passivos da série de acontecimentos infelizes relatados no trecho 2. Essa conduta de passividade levantada pela autora tem um caráter nebuloso, podendo ser entendida de forma positiva (nesse momento de caos, não participamos desse circo de horrores) ou negativa (não estamos fazendo algo para mudar a situação).

Para dar sustentação argumentativa a essa construção discursiva, a autora lança mão de construtos avaliativos pautados em julgamentos negativos de sanção social que abrangem aqueles que deveriam aplicar a lei, mas não o fazem; a mídia cuja cobertura dos eventos em questão é enviesada, prestigiando interesses plutocráticos; e, por fim, o congresso que, no auge da intensidade gradativa do julgamento da autora, transformou a votação de um processo já ilegítimo num show de horror e falta de respeito à população.

Torna-se relevante voltar nossa atenção também à forma como a autora aprecia o processo de votação da matéria do impeachment da Presidenta Dilma Rousseff. Observo um movimento de aumento de intensidade na gradação dessa apreciação negativa. A princípio, o processo já é qualificado pelo modificador ilegítimo, que vincula-se ao contexto da matéria votada pelos deputados no que tange à possibilidade do processo de impeachment até poder ser interpretado como um dispositivo legal, porém, não estando respaldado em critérios de 
legitimidade. Em seguida, a autora faz uso de mais um elemento gradativo, deflagrando uma transformação negativa. O processo de impeachment, já marcado pela ilegitimidade, agora sofre uma segunda gradação, tornando-se um show de horror. Dessa forma, a apreciação negativa da autora desloca-se do campo da análise a partir de critérios de caráter técnico do direito (legalidade e legitimidade) e aproxima-se de um juízo de valor estético marcado por uma metáfora gramatical (show de horror) cuja utilização visa inspirar desconforto no leitor do texto.

Por fim, a autora constrói seu último momento de julgamento, expandindo o círculo de pertencimento do seu grupo (nós) a toda a população brasileira (ingroupness) ao afirmar que o comportamento dos participantes do show de horror é desrespeitoso a todo o povo brasileiro. Dessa forma, a escritora do texto 2 articula sua argumentação de forma a não apenas deslegitimar o ato dos outros, como também reforçar a legitimidade do grupo ao qual ela se afilia ao incluir o leitor nesse mesmo coletivo (da população desrespeitada por eles). Voltemos nossa atenção agora à presença do Engajamento.

\section{Análise do Engajamento na construção de identidades a partir da distinção nós e outros}

Uma outra ferramenta teórica que nos oferece meios para observarmos a construção da polarização e radicalização no discurso político presente nos textos destacados encontra-se, ainda, no Sistema de Avaliatividade (MARTIN; WHITE, 2005), mais especificamente, no subsistema de Engajamento. Partindo da perspectiva bakhtiniana de que todo discurso é dialógico, apoio-me nesse construto teórico, integrante do Sistema de Avaliatividade, para entender o quanto os autores dos dois textos aqui abordados comprometem-se com suas afirmações e posicionamentos. Nesse sentido, destaco abaixo dois trechos representativos da função do engajamento discursivo na construção argumentativa e identitária.

\section{Trecho 3}

\begin{tabular}{|l|l|}
\hline 13 & Pouco antes, os brucutus haviam cercado uma estrutura armada para o \\
15 & trabalho de jornalistas e fotógrafos, ameaçando derrubá-la, aos gritos de \\
16 & "Jornalia golpista". Entrei no site da Fenaj - Federação Nacional dos \\
\end{tabular}


Trecho 4

\begin{tabular}{|l|l|}
\hline 16 & Segundo Lilia Ferreira, estudante da Universidade Estadual de Alagoas e \\
17 & feminista, o deputado Ricardo Nezinho (PMDB) justifica a criação do \\
18 & projeto de lei alegando haver doutrinação ideológica por parte dos \\
19 & professores e livros didáticos, em suas palavras, "para fazer com que eles \\
20 & adotem padrões de julgamento e de conduta moral - especialmente moral \\
21 & $\begin{array}{l}\text { sexual - incompatíveis com os que lhes são ensinados por seus pais ou } \\
\text { responsáveis." }\end{array}$
\end{tabular}

Texto 2: Carta Capital online, 11/05/2016

Uma mirada holística voltada ao texto 1 nos possibilita observar que o texto é baseado num padrão de contração dialógica, onde as vozes que embasaram a argumentação do autor se mantém, na maior parte do texto, ocultas e espaços para possíveis contrapontos e diferentes perspectivas são ceifados. No trecho 3, observamos um dos poucos momentos em que o autor permite a introdução da voz dos manifestantes (alvos de suas críticas ao longo texto). No entanto, tal abertura não é concedida sem antes tecer julgamentos depreciativos de alta gradação acerca desses indivíduos, qualificando-os como brucutus e atribuindo a eles comportamentos violentos. Ao trazer à tona seu interesse no posicionamento da Fenaj, o autor insinua para seus leitores que alguma comunicação por parte da federação nacional dos jornalistas deveria ter sido emitida. No entanto, a nota de repúdio buscado pelo jornalista não foi encontrada, sendo substituída, no trecho em destaque, pelo item lexical Nada, acompanhado do sinal de exclamação como um sinal de acentuação afetiva acerca dessa palavra.

Como pudemos observar, o texto 1 é marcado por uma postura argumentativa incisiva do autor, que, nessa ótica, concede poucos espaços para a heteroglossia e a reflexão em seu discurso. No texto 2, notamos uma construção argumentativa que se movimenta em sentido contrário e nos apresenta um exemplo interessante de expansão dialógica: a autora cede espaço em seu discurso para veicular uma voz que traz a fala de um terceiro. Tal movimento argumentativo e heteroglóssico elaborado pela autora atua na construção da imagem de uma pessoa democrática e reflexiva, criando a impressão de seu texto ser uma compilação de diversas vozes antes de um veículo de promoção de ideias pessoais. Ambos os personagens cujas vozes são apresentadas no trecho 4 recebem qualificação avaliativa da jornalista, ajudando a delinear de forma mais candente as fronteiras onde se ancoram as afiliações político-ideológicas da autora. Dessa maneira, a voz privilegiada pertence a Lilia Ferreira, detentora de certas características que a inserem no mesmo grupo (ingroupness) ao qual a jornalista se alinha. Por outro lado, o segundo personagem apresentado no parágrafo em questão, cuja voz é distorcida a partir de sucessivos recortes, não goza da mesma legitimidade 
de Lilia. Ricardo é descrito um operador da política afiliado a um partido conhecido por seu viés conservador, sendo, portanto, inserido discursivamente no grupo dos outros.

O texto 2 apresenta um discurso altamente heteroglóssico com o prestígio de diversas vozes ao longo da construção argumentativa da autora. Buscando analisar as razões pragmáticas das escolhas léxico-gramaticais realizadas pela escritora, evidenciadas com a ajuda do ferramental teórico de que dispomos nessa pesquisa, observo que a opção por um texto dialogicamente expandido é justificada pelo interesse da autora em relacionar elementos de tolerância e democracia ao seu próprio discurso. Ao criticar veementemente certos setores da sociedade brasileira por sua violência e aversão às diferenças, a jornalista busca expressar seu desprezo por esse posicionamento tirânico, não apenas nas escolhas lexicais de seu texto, mas, principalmente, em sua própria estrutura. Dessa forma, a autora constrói uma identidade de jornalista que amplifica as diferentes vozes e clamores que ecoam dos movimentos sociais nas ruas.

\section{IMAGENS E IDENTIDADES CONSTRUÍDAS: A DISTINÇÃO NÓS $x$ OUTROS E SEU PAPEL POTENCIAL NA PROMOÇÃO DO LETRAMENTO CRÍTICO}

Como explicado na seção introdutória, a presente pesquisa encontra sua inspiração na efervescência que inunda o quadro político brasileiro contemporâneo e na constatação da importância de municiar os alunos com elementos analíticos que lhes deem condições de observarem criticamente posicionamentos políticos e ideológicos que permeiam qualquer texto, mesmo quando escondidos em meio a uma suposta névoa de neutralidade. Nesse sentido, a análise aqui apresentada buscou oferecer um exemplo a ser transposto da academia para a sala de aula.

A partir de um olhar investigativo acerca dos textos aqui destacados, evidenciou-se a forma como a manipulação dos julgamentos negativos e positivos, tanto em seu direcionamento quanto em sua gradação, foi articulada visando a construção de uma imagem de divisão da sociedade brasileira em grupos antagônicos a partir dos interesses de cada autor. Da mesma maneira, a dinâmica de expansão ou contração dialógica foi construída de forma a articular interesses que, em determinados momentos, demandavam construções identitárias de caráter mais democrático, portanto, portadoras de discursos mais heteroglóssicos enquanto, em outros contextos, legitimavam uma identidade mais engajada e militante, amparada por um texto consequentemente mais contraído dialogicamente. 
Esses resultados, expostos acima, evidenciam a importância de articular os insumos analíticos apresentados nessa pesquisa com uma proposta de promoção de letramento crítico. Essa ideia encontra eco na colocação de Predebon (2015), no momento em que a autora considera que "Promover propostas pedagógicas de natureza crítica, (...), significa investigar com o mesmo rigor tanto os aspectos linguísticos e textuais que materializam os eventos comunicativos quanto a dinâmica contextual [grifo meu] que gera os textos." Ancorado nessa visão, considero importante que a pesquisa acadêmica expanda seu raio de alcance e insira-se também na sala de aula, no caso aqui apresentado, especificamente, no contexto de ensino de língua portuguesa. Visando atender a essa perspectiva, proponho algumas sugestões de perguntas orientadas para a promoção do letramento crítico, tendo como base estrutural o modelo desenvolvido por Cervetti, Pardales e Damico (2001) e exposto abaixo:

Quadro 1 - perguntas orientadas para a promoção do letramento crítico

- Como os significados são associados a determinado dado ou evento em um texto?

- Como o texto busca fazer com que os leitores aceitem suas representações?

- Qual o objetivo do texto?

- Aos interesses de quem a disseminação desse texto serve? Aos interesses de quem esse texto não serve?

- Que visão de mundo é representada pelas ideias no texto? Que visão de mundo não é representada?

Ancorado nas análises apresentadas, nos pressupostos teóricos e ferramentais analíticos que embasaram a presente pesquisa; e guiado pelo modelo estrutural e metodológico exposto acima, proponho uma série de perguntas fomentadoras de reflexão discente. Articuladas às atividades pedagógicas construídas pelo docente, essas questões visam oferecer insumos de análise textual que entenda o texto na complexidade dialética de suas relações sociais, promovendo, dessa forma, um processo de letramento crítico. Essa proposta é apresentada abaixo:

Quadro 2 - Sugestões de perguntas orientadas para a promoção de letramento crítico, baseadas na Linguística Sistêmico-Funcional em diálogo com a noção de nós e outros

- É possível identificar julgamentos no texto? Que tipo de julgamentos podem ser encontrados? É possível identificar o(s) alvo(s) desse julgamento? O(A) autor(a) do 


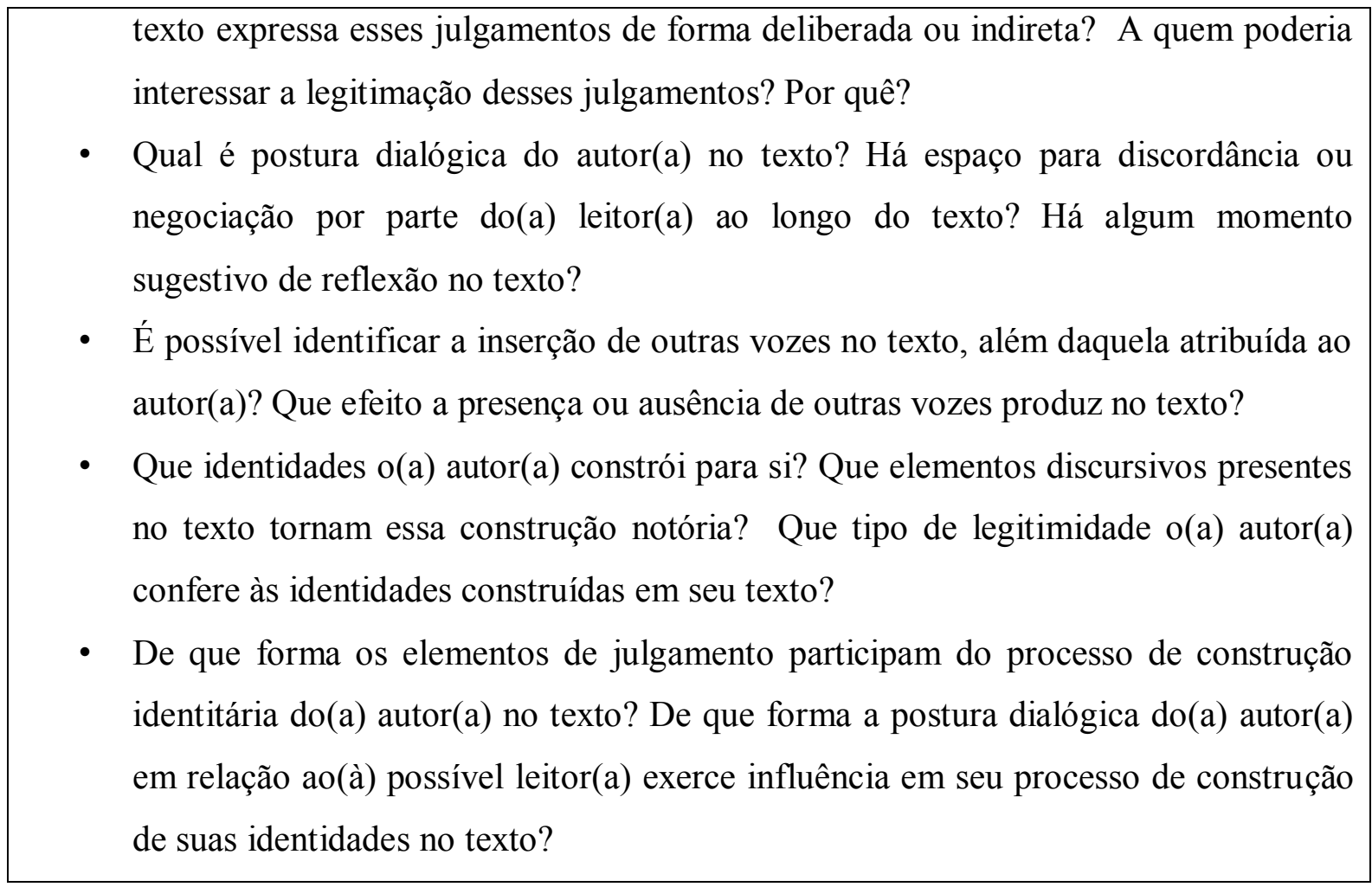

Essas sugestões de perguntas reflexivas não visam oferecer ao professor uma fórmula ou receita pedagógica que deva ser aplicada a qualquer atividade e em qualquer contexto. Pelo contrário, essa percepção contrariaria a premissa de uma visão crítica. Acredito, inclusive, que essas questões (ou qualquer outro elemento a ser integrado à prática do professor) também devem ser continuamente criticadas acerca de sua relevância ou solidez teórica pelo docente em sua prática. O objetivo central desses questionamentos é contribuir para a promoção de um processo de letramento crítico, a partir da inclusão de uma perspectiva teórico-analítica baseada num ferramental que privilegia um entendimento de texto em sua relação dialética com os elementos sociais e políticos que lhe dão sustentação.

\section{REFERÊNCIAS}

ABREU, A. R. Vozes de julgamento como pontos de argumentação na produção escrita de alunos do ensino médio: abordagem sociodiscursiva e sociossemiótica. Dissertação de Mestrado, PUC-Rio, 2013.

BAKHTIN, M. Estética da criação verbal. Tradução: Paulo Bezerra. São Paulo: Martins Fontes, 2003.

BAUMAN, Zygmunt. Medo líquido. Rio de Janeiro: Jorge Zahar, 2008. 
BRETON, P. A argumentação na comunicação. Tradução: Viviane Ribeiro. São Paulo: EDUSC, 2003.

CERVETTI, G.; PARDALES, M. J.; DAMICO, J. S. A tale of differences: comparing the traditions, perspectives and educational goals of critical reading and critical literacy. Reading Online, v. 4, n. 9, 2001. Disponível em:

http://www.readingonline.org/articles/art index.asp?HREF=articles/cervetti/index.html

DUSZAK, A. Us and others. Social Identities across languages, discourses and cultures. (Introdução). Amsterdam/Philadelphia: John Benjamins, 2002.

GOUVEIA, C.A.M. Texto e gramática: uma introdução à Linguística Sistêmico-Funcional. Matraga, v. 16, n. 24, p. 13-47, 2009.

HALLIDAY, M. A. K. An Introduction to Functional Grammar. 2 ed. London: Arnold, 1994.

MARTIN, J. R.; WHITE, P. The language of evaluation. Great Britain: Pelgrave/ Macmillan, 2005.

NÓBREGA, A. N. Narrativa e identidade: Contribuições da avaliação no processo de (re)construção identitária em sala de aula universitária. Veredas Atemática v. 16, n. 2, p. 6884,2012

NÓBREGA, A.N.; ABREU, A.R. Análise crítica da construção de identidades na prática escrita escolar. Calidoscópio, v. 13, n. 2, p. 251-263, 2015.

NÓBREGA, A; MAGALHÃES, C. Narrativa e Identidade: contribuições da avaliação no processo de (re-) construção identitária em sala de aula universitária. Veredas on-line atemática. PPG, Linguística, UFJF, 2012.

OLIVEIRA, H.Q. Alunos em situação de retenção reconstruindo o cotidiano escolar: um estudo sobre avaliação e identidade em pequenas histórias. Dissertação de mestrado, PUC-Rio, 2015.

PREDEBON, N.R.C. Do entretenimento à crítica: letramento multimodal crítico no livro didático de inglês com base em gêneros dos quadrinhos. Tese de doutorado Universidade Federal de Santa Maria - RS, 2015.

SOBRINHO, C. G. P. A construção das identidades do professor em greve: uma análise crítica e sistêmico-funcional do discurso avaliativo de reportagens jornalísticas. Dissertação de mestrado, PUC-Rio, 2015.

\section{O AUTOR}

Diego Candido Abreu é mestrando em Estudos da Linguagem na Pontifícia Universidade Católica do Rio de Janeiro e bolsista CNPq. Fez a graduação em Letras (Português/Inglês, Licenciatura) pela UERJ. Trabalhou como Professor de Língua Inglesa no município de 
Saquarema. Suas áreas de interesse compreendem Linguística Aplicada, Linguística Sistêmico-Funcional, Letramento Crítico, Discurso Político, Ensino/Aprendizagem de Línguas e Afeto/Emoção numa perspectiva discursiva.

E-mail: diegocurciodeabreu@gmail.com 